\title{
Honey and Cancer: Sustainable Inverse Relationship Particularly for Developing Nations-A Review
}

\author{
Nor Hayati Othman \\ Department of Pathology, Universiti Sains Malaysia, Kelantan, 16150 Kubang Kerian, Malaysia \\ Correspondence should be addressed to Nor Hayati Othman, hayati@kb.usm.my \\ Received 13 November 2011; Accepted 6 May 2012 \\ Academic Editor: Alyson Huntley
}

Copyright (C) 2012 Nor Hayati Othman. This is an open access article distributed under the Creative Commons Attribution License, which permits unrestricted use, distribution, and reproduction in any medium, provided the original work is properly cited.

\begin{abstract}
Honey and cancer has a sustainable inverse relationship. Carcinogenesis is a multistep process and has multifactorial causes. Among these are low immune status, chronic infection, chronic inflammation, chronic non healing ulcers, obesity, and so forth. There is now a sizeable evidence that honey is a natural immune booster, natural anti-inflammatory agent, natural antimicrobial agent, natural cancer "vaccine," and natural promoter for healing chronic ulcers and wounds. Though honey has substances of which the most predominant is a mixture of sugars, which itself is thought to be carcinogenic, it is understandable that its beneficial effect as anticancer agent raises skeptics. The positive scientific evidence for anticancer properties of honey is growing. The mechanism on how honey has anticancer effect is an area of great interest. Among the mechanisms suggested are inhibition of cell proliferation, induction of apoptosis, and cell-cycle arrest. Honey and cancer has sustainable inverse relationship in the setting of developing nations where resources for cancer prevention and treatment are limited.
\end{abstract}

\section{Cancer: The Global Epidemic}

Cancer is a global epidemic. In 2008, it was estimated there were 12,332,300 cancer cases of which 5.4 million were in developed countries and 6.7 million were in developing countries [1] (Figure 1). Over half of the incident cases occurred in residents of four WHO regions. The world population increased from 6.1 billion in 2000 to 6.7 billion in 2008 [2]. The increase in populations was much more in developing countries than in developed countries. Even if the age-specific rates of cancer remain constant, developing countries would have a higher cancer burden than developed countries.

Cancer trends are showing upward trends in many developing countries [3-5] and a mixed pattern in developed countries [6-8]. By 2050, the cancer burden could reach 24 million cases per year worldwide, with 17 million cases occurring in developing countries [9]. Cancers which are associated with diet and life style are seen more in developed countries while cancers which are due to infections are more in developing countries. According to the World Health
Organization (WHO), death from cancer is expected to increase to $104 \%$ worldwide by 2020 .

While the number of total cancer is increasing, the trend of certain cancers is changing in developed and developing countries. In developed countries, the trend is declining [10] since infections by microorganisms are declining and screening facilities are available. In Singapore, there was an average annual increase of 3.6\% for breast cancers in women in the 1988-1992 period [11]. In Qatar, there was a 57.1\% rise of cancers 1991-2006 [12], and in Netherlands, there was an increase between 1.9\% (females) and 3.4\% (males) per year for oesophageal cancer 1989-2003 [13].

In order to understand the usefulness of honey in cancer, we need to understand the various factors which could cause cancer. Carcinogenesis is a multi-step process and has multifactorial causes. Development of cancers takes place long after initiation, promotion, and progression steps (Figure 2) have taken place. The cellular damage could be by one factor or multiplicity of these factors. The latter is more frequent. Cancer development could occur 10-15 years after exposure to the risk factors. 


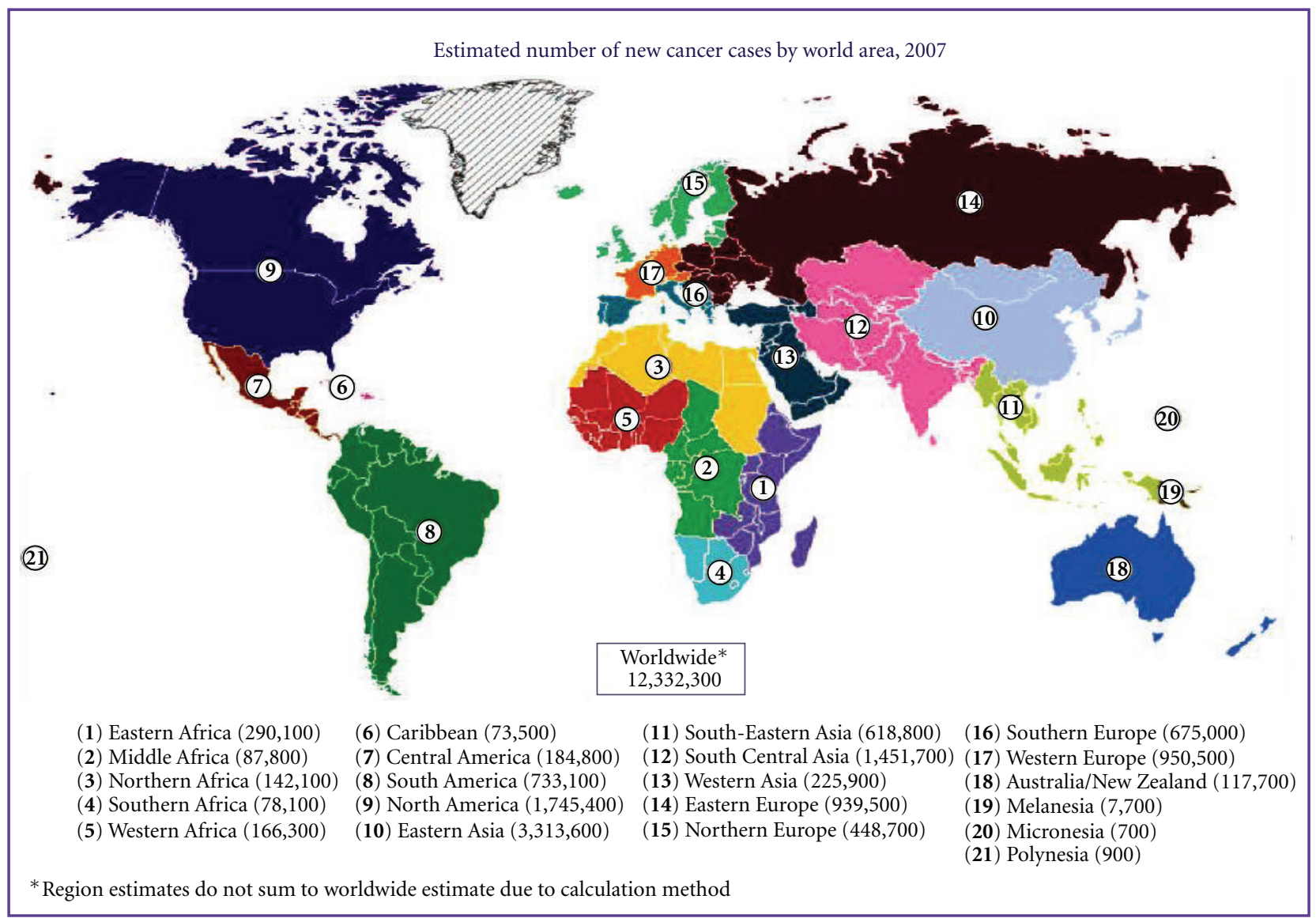

FiguRE 1: Estimated new cancer cases by world areas (source: Global Cancer Facts and Figures 2007).

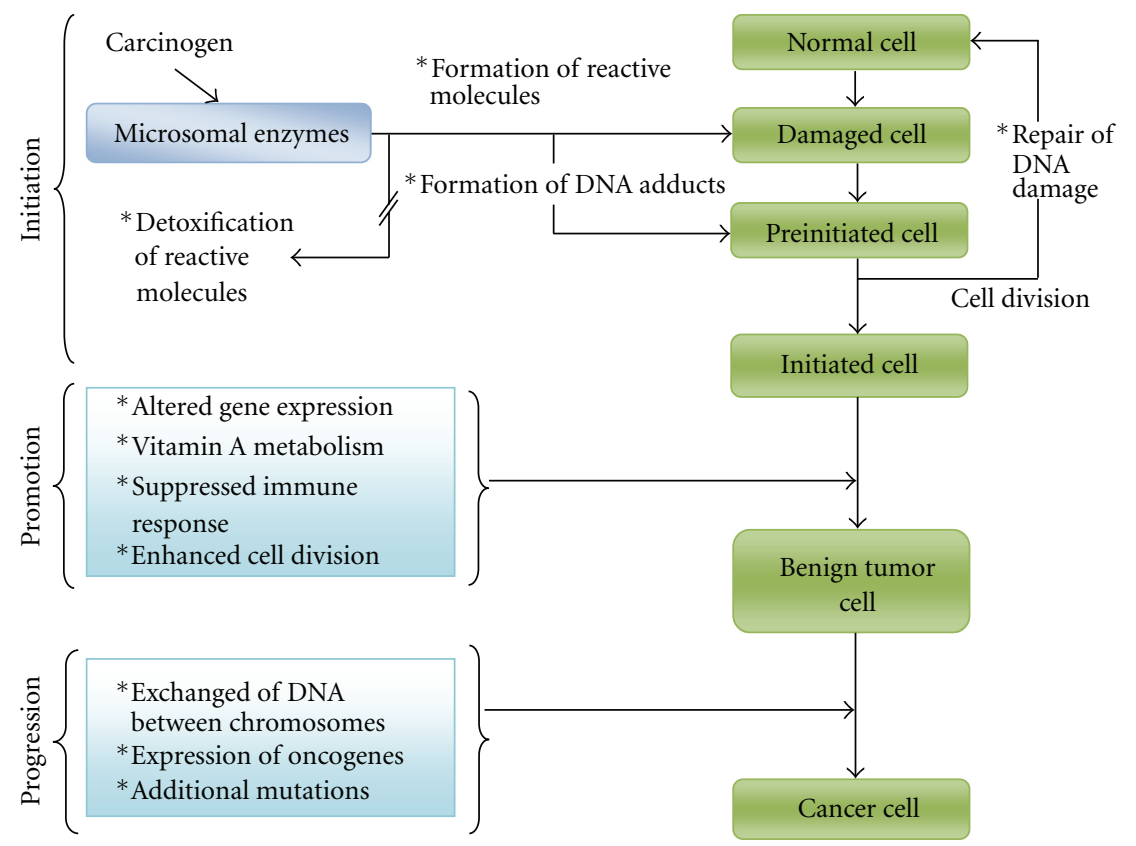

Figure 2: Steps in carcinogenesis. *Steps altered by alcohol consumption (Source: Garro et al. Alcohol Health \& Research World 16(1):81-86, 1992). 
1.1. Life-Style Habits/Diseases as Risks to Cancer Development. Cancer is caused by genetic damage in the genome of cells. This damage is either inherited or acquired throughout life. The acquired genetic damage is often "self-inflicted" through unhealthy lifestyles. Essentially one-third of cancer is due to tobacco use, one-third due to dietary and lifestyle factors, and one-fifth due to infections. Other factors include chemical carcinogens, environmental pollutants, and alcohol (Figure 3). In the developing countries, cancers caused by infections by microorganisms such as cervical (by human papilloma virus) [14], liver (by hepatitis viruses) [15], nasopharynx (by Epstein-Barr virus) [16], and stomach (by Helicobacter pylori) [17] are more common than those in developed countries [18]. While cancers of the prostate, breasts, and colorectal are clearly more prevalent in developed than developing countries, the distinction is not very apparent as that for cancer of the lung which is as prevalent as that in more or less developed nations. Except for breast cancers, the top 5 cancers in males and females of developing nations are due to life-styles or infections [18].

1.1.1. Smoking and Tobacco Use. Association of cancer to cigarette smoking is beyond doubt. The prevalence of smoking is higher in developing than that in developed countries [19]. Smoking is associated with a number of cancers such as larynx, bladder, breasts, oesophagus, and cervix. While in developed countries the prevalence of smoking is decreasing [20], the scenario is the reverse in developing countries. The initiation and the influence to start smoking are similar to those in developed countries [21]. Smoking increases the risk of colorectal carcinomas by $43 \%$ [22]. Ever-smokers were associated with an 8.8-fold increased risk of colorectal cancers (95\% confidence interval, 1.7-44.9) when fed on well-done red meat diet if they have NAT2 and CYP1A2 rapid phenotypes [23]. No similar association was found in neversmokers [23].

1.1.2. Obesity and Physical Inactivity. Obese subjects have an approximately 1.5-3.5-fold increased risk of developing cancers compared with normal-weight subjects [24]. Obesity is associated in a number of cancers $[25,26]$ particularly endometrium $[27,28]$, breasts $[29,30]$, and colorectal cancers [31]. Adipocytes have the ability to enhance the proliferation of colon cancer cells in vitro [32]. The trend of prevalence of overweight/obesity is rising in many developed and developing countries [33]. In a study conducted in 2005 [34] in the Kota Bharu district in the state of Kelantan Malaysia, the overall prevalence of overweight/obesity was $49.1 \%$ [34], much higher than the figure reported earlier in 1996 [35]. In this community, the rise of cancer is exponential in the period from year 2002 to 2007 (143.6\% increment) compared to the previous 5-year period of 1996 2001 [36].

Obesity is not a social problem but a disease. The greatest risk is for obese persons who are also diabetic, particular those whose body mass index is above $35 \mathrm{~kg} / \mathrm{m}^{2}$. The increase in risk is by 93 -fold in women and by 42 -fold in men [37].
1.1.3. Diabetes Particularly Type 2 as Risk for Cancer Development. Obesity is closely related with diabetes [38]. A community that has high prevalence of obesity also has high prevalence of diabetes [36]. In Kelantan, Malaysia, the prevalence of diabetes in 1999 was 10.5\%, and impaired glucose tolerance was $16.5 \%$ [39]. Kelantan is ranked highest in prevalence of diabetes in Malaysia in which the overall national prevalence is $8.3 \%$ [40], thus it was not a surprise to see a rapid rise of cancer prevalence in the state [36]. According to a review on diabetes, the WHO has estimated that, by 2030, there would be 2.48 million diabetics in Malaysia, a jump of $164 \%$ from 0.94 million in 2002 [41]. One of the most common cancers noted in community that has high diabetics and obesity is colorectal cancer [42-45].

In a study of 138 colorectal cancers (CRC) seen in Hospital Universiti Sains Malaysia, 47.8\% had metabolic diseases, of which $13.8 \%$ were diabetes type 2 [42]. Those diabetics with CRC often have distal cancers [42].

1.2. Chronic Infections as Risk for Cancer Development. There are a number of microorganisms which could cause cancer. Common viruses causing cancers [46] are Epstein-Barr virus (EBV) [47] (nasopharyngeal carcinomas), human papilloma virus (cervical cancers and other squamous cancers) and Hepatitis B viruses (liver cancers). Viruses are oncogenic after long period of latency [48].

Bacteria which has been studied to have associations with cancer are Helicobacter pylori infections (stomach cancer) [17], Ureaplasma urealyticum (prostate cancer) [49], and chronic typhoid carrier (gall bladder cancer) [50]. Chronic fungi infections have also been studied to be associated with cancer [51]. Parasites such as Schistosoma haematobium are associated with carcinoma of the urinary bladder; liver flukes Opisthorchis viverrini and Clonorchis sinensis associated with cholangiocarcinoma and hepatocellular carcinoma. There are three main mechanisms by which infections can cause cancer. They appear to involve initiation as well as promotion of carcinogenesis [52]. Persistent infection within host induces chronic inflammation accompanied by formation of reactive oxygen and nitrogen species (ROS and RNOS) [52]. ROS and RNOS have the potential to damage DNA, proteins, and cell membranes. Chronic inflammation often results in repeated cycles of cell damage leading to abnormal cell proliferation [53]. DNA damage promotes the growth of malignant cells. Secondly, infectious agents may directly transform cells, by inserting active oncogenes into the host genome, inhibiting tumour suppressors or stimulating mitosis [52]. Thirdly, infectious agents, such as human immunodeficiency virus (HIV), may induce immunosuppression [52].

\section{Low Immune Status as Risk of Cancer Development}

2.1. Cancer and Aging. The most important change that would occur in the world population in the next 50 years is the change in the proportion of elderly people (more than 65 years): $7 \%$ in 2000 to $16 \%$ in 2050 [54]. Many cancers 


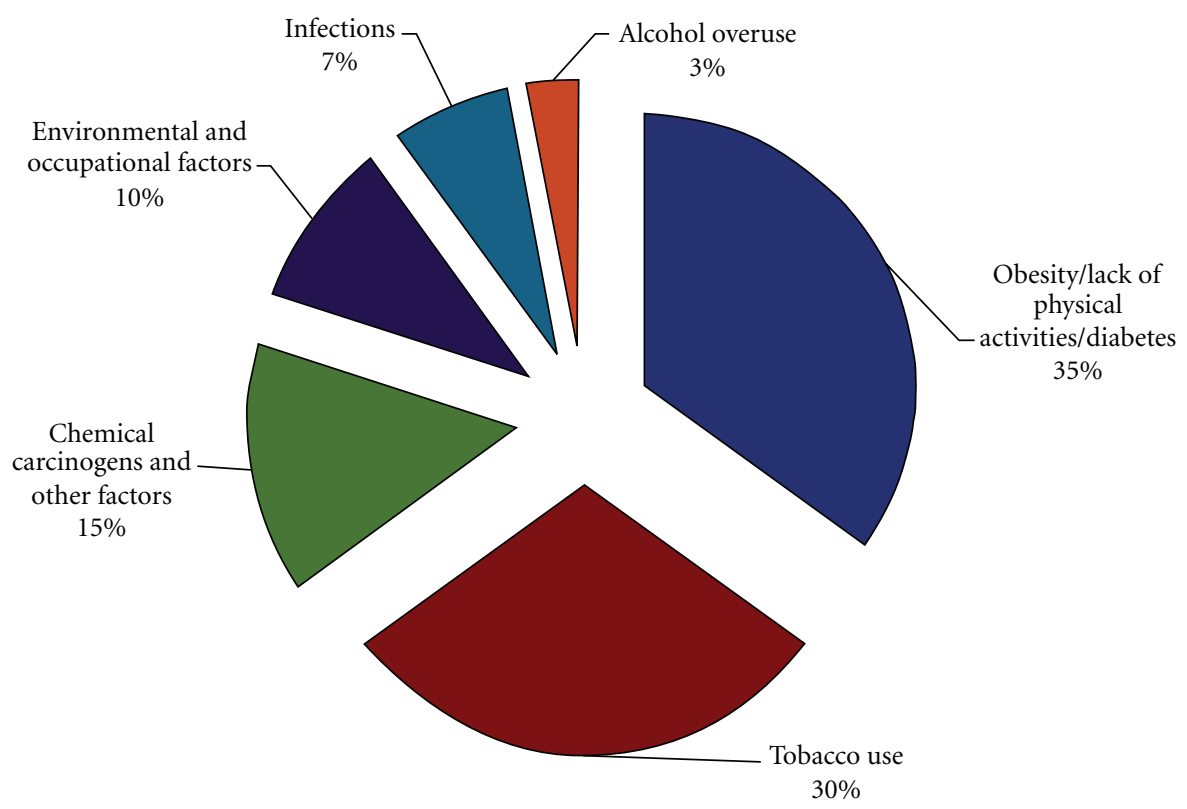

Figure 3: The acquired risk factors of cancer development.

are associated with aging. Although age per se is not an important determinant of cancer risk, it implies prolonged exposure to carcinogen [55]. By the year 2050, 27 million people are projected to have cancer. More than half of the estimated number will be residents of developing countries [54]. Aging is also associated with reduced immune system.

\subsection{Low Immune Status due to Chronic Diseases. Patients} who have low immune system are at risk for cancer development. This explains why diabetics are more at risk than non-diabetics to get epithelial cancers. HIV patients are at risk to develop epithelial and nonepithelial cancers. These persons are also at risk to develop multiple chronic infections implying the multiplicity in cancer genesis. Patients with autoimmune diseases are also at risk to develop cancers such as colorectal carcinomas in ulcerative colitis and Crohn's disease and thyroid cancer in autoimmune thyroiditis.

2.3. Chronic Ulcers and Wounds. Chronic ulcers have risk to develop cancer. The most common is Marjolin's ulcer [56], and they are common in developing nations especially in rural areas with poor living conditions [57]. This risk factor is related to chronic infections as most if not all chronic ulcers are not healing because of persistent infections.

\section{What Is Honey and Why Is It Useful against Cancer? (See Figure 4)}

Honey is known for centuries for its medicinal and healthpromoting properties. It contains various kinds of phytochemicals with high phenolic and flavonoid content which contribute to its high antioxidant activity [58-60]. Agent that has strong antioxidant property may have the potential to prevent the development of cancer as free radicals and oxidative stress play a significant role in inducing the formation of cancers [61]. Phytochemicals available in honey could be narrowed down into phenolic acids and polyphenols. Variants of polyphenols in honey were reported to have antiproliferative property against several types of cancer [62].

\section{Honey As a Natural Immune Booster}

Honey stimulates inflammatory cytokine production from monocytes [63]. Manuka, pasture, and jelly bush honey were found to significantly increase TNF- $\alpha$, IL- $1 \beta$, and IL6 release from MM6 cells (and human monocytes) when compared with untreated and artificial honey-treated cells $(P<0.001)$ [63]. A $5.8 \mathrm{kDa}$ component of manuka honey was found to stimulate cytokine production from immune cells via TLR4 [64]. Honey stimulates antibody production during primary and secondary immune responses against thymus-dependent and thymus-independent antigens in mice injected with sheep red blood cells and E. coli antigen [65]. Consumption of $80 \mathrm{~g}$ daily of natural honey for 21 days showed that prostaglandin levels compared with normal subjects were elevated in patient with AIDS [66]. Natural honey has been shown to decrease prostaglandin level, elevated NO production in patients with a long history of AIDS [66]. It was reported that oral intake of honey augments antibody productions in primary and secondary immune responses against thymus-dependent and thymusindependent antigens [67].

These studies suggest that daily consumption of honey improves one's immune system.

\section{Honey As Natural Anti-Inflammatory Agent}

In routine everyday life, our cells may be injured by irritants from outside or within our bodies (by microbes or nonmicrobes). Cellular/molecular injuries result in inflammatory 


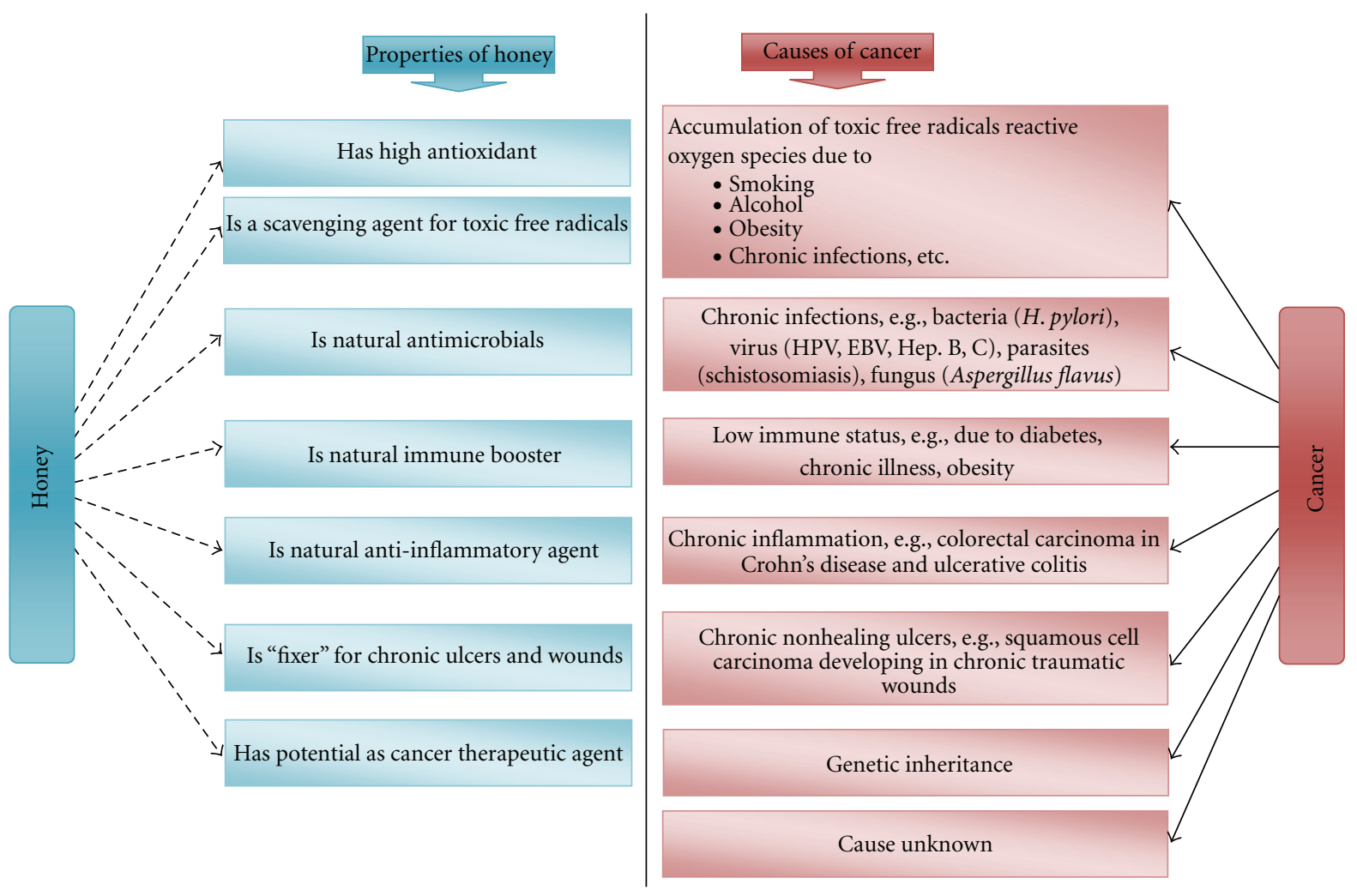

FIGURE 4: The inverse relationship of honey and cancer.

response, the body defense mechanisms in trying to rid of the irritants. In general inflammatory responses are beneficial and protective to us, but at times, inflammatory responses are detrimental to health. Honey is a potent antiinflammatory agent. Infants suffering from diaper dermatitis improved significantly after topical application of a mixture containing honey, olive oil, and beeswax after 7 days [68]. Honey provides significant symptom relief of cough in children with an upper respiratory tract infection (URTI) [69]. It has been shown to be effective in management of dermatitis and Psoriasis vulgaris [70]. Eight out of 10 patients with dermatitis and five of eight patients with psoriasis showed significant improvement after 2 weeks on honey-based ointment [70]. Honey at dilutions of up to $1: 8$ reduced bacterial adherence from $25.6 \pm 6.5$ (control) to $6.7 \pm 3.3$ bacteria per epithelial cell $(P<0.001)$ in vitro [71]. Volunteers who chewed "honey leather" showed that there were statistically highly significant reductions in mean plaque scores ( 0.99 reduced to $0.65 ; P=0.001)$ in the manuka honey group compared to the control group suggesting a potential therapeutic role for honey for gingivitis, periodontal disease [72], mouth ulcers, and other problems of oral health [73].

A case report of a patient who had chronic dystrophic epidermolysis bullosa (EB) for 20 years healed with honey impregnated dressing in 15 weeks [74] after conventional dressings and creams failed. This illustrates the usefulness of honey as an anti-inflammatory agent. Chronic inflammatory process has risk of cancer development.

\section{Honey As Natural Antimicrobials}

Everyday we are exposed to all kinds of microbial insults from bacteria, viruses, parasites, and fungi. Honey is a potent natural antimicrobial. The most common infections humans get are from staphylococcal infection. Antibacterial effect of honey is extensively studied. The bactericidal mechanism is through disturbance in cell division machinery [75]. The minimum inhibitory concentration (MIC) for Staphylococcus aureus by A. mellifera honey ranged from 126.23 to $185.70 \mathrm{mgml}^{-1}$ [76]. Honey is also effective against coagulase-negative staphylococci [77]. Local application of raw honey on infected wounds reduced signs of acute inflammation [78], thus alleviating symptoms. Antimicrobial activity of honey is stronger in acidic media than in neutral or alkaline media [78]. The potency of honey is comparable to some local antibiotics. Honey application into infective conjunctivitis reduced redness, swelling, pus discharge, and time for eradication of bacterial infections [78]. When honey is used together with antibiotics, gentamycin, it enhances anti-Staphylococcus aureus activity, by $22 \%$ [79]. When honey is added to bacterial culture medium, the appearance of microbial growth on the culture plates is delayed [80]. Mycobacteria did not grow in culture media containing $10 \%$ and $20 \%$ honey while it grew in culture media containing $5 \%, 2.5 \%$, and $1 \%$ honey, suggesting that honey could be an ideal antimycobacterial agent [81] at certain concentrations. 
Honey is also effective in killing hardy bacteria such as Pseudomonas aeruginosa (PA) and could lead to a new approach in treating refractory chronic rhinosinusitis [82]. Daily consumption of honey reduces risk of chronic infections by microorganisms. Chronic infections have risk for cancer development.

There are three main mechanisms by which infections can cause cancer. They appear to involve initiation as well as promotion of carcinogenesis [52]. Persistent infection within host induces chronic inflammation accompanied by formation of reactive oxygen and nitrogen species (ROS and RNOS) [52]. ROS and RNOS have the potential to damage DNA, proteins, and cell membranes. Chronic inflammation often results in repeated cycles of cell damage leading to abnormal cell proliferation [53]. DNA damage promotes the growth of malignant cells. Secondly, infectious agents may directly transform cells, by inserting active oncogenes into the host genome, inhibiting tumour suppressors [52]. Thirdly, infectious agents, such as human immunodeficiency virus (HIV), may induce immunosuppression [52].

The effectiveness of honey is best when used at room temperature. Heating honey to 80 degrees for 1 hour decreased antimicrobial activity of both new and stored honey. Storage of honey for 5 years decreased its antimicrobial activity, while ultraviolet light exposure increased its activity against some of microorganisms [78].

Honey also has been shown to have antiviral properties. In a comparative study topical application of honey was found to be better than acyclovir treatment on patients with recurrent herpetic lesions [83]. Two cases of labial herpes and one case of genital herpes remitted completely with the use of honey while none with acyclovir treatment [83].

\section{Honey As Possible Agent for Controlling Obesity}

Obese individuals are at risk to develop cancer. There is a close link among obesity, a state of chronic low-level inflammation, and oxidative stress [84]. Obese subjects have an approximately 1.5-3.5-fold increased risk of developing cancers compared with normal-weight subjects [2426] particularly endometrium [27, 28], breasts [29, 30], and colorectal cancers [31]. Adipocytes have the ability to enhance the proliferation of colon cancer cells in vitro [32]. The greatest risk is for obese persons who are also diabetic, particularly those whose body mass index is above $35 \mathrm{~kg} / \mathrm{m}^{2}$. The increase in risk is by 93 -fold in women and by 42 -fold in men [37]. One of the most common cancers noted in community that has high diabetics and obesity is colorectal cancer [42-45].

In a clinical study on 55 overweight or obese patients, the control group (17 subjects) received $70 \mathrm{~g}$ of sucrose daily for a maximum of 30 days and patients in the experimental group (38 subjects) received $70 \mathrm{~g}$ of natural honey for the same period. Results showed that honey caused a mild reduction in body weight $(1.3 \%)$ and body fat (1.1\%) [85]. Beneficial effect of honey on obesity is not well established thus far.

\section{Honey as "Fixer" for Chronic Ulcers and Wounds}

Increasing numbers of antibiotic-resistant bacteria has made simple wounds become chronic and non-healing and as such honey provides alternative treatment options [86]. Honey absorbs exudates released in wounds and devitalized tissue [87]. Honey is effective in recalcitrant surgical wounds [88]. It increases the rate of healing by stimulation of angiogenesis, granulation, and epithelialization, making skin grafting unnecessary and giving excellent cosmetic results [89]. In a randomized control trial, Manuka honey improved wound healing in patients with sloughy venous leg ulcers [90]. Honey was shown to eradicate MRSA (Methylene resistant Staphylococcus aureus) infection in 70\% of chronic venous ulcers [91]. Honey is acidic and chronic non healing wounds have an elevated alkaline environment. Manuka honey dressings is associated with a statistically significant decrease in wound $\mathrm{pH}$ [92]. Available evidence in metaanalysis studies indicates markedly greater efficacy of honey compared with alternative dressings for superficial or partial thickness burns [93]. Honey is an inexpensive moist dressing with antibacterial and tissue-healing properties suitable for diabetic foot [94]. The average cost of treatment per patient using honey dressing is much cheaper with conventional dressing [95].

\section{Honey As Natural Cancer "Vaccine"}

Synthetic vaccines like BCG or polio vaccine work by preventing vaccinated subjects from contracting tuberculosis and poliomyelitis. Honey has the element of a "natural cancer vaccine" as it can reduce chronic inflammatory processes, improve immune status, reduce infections by hardy organisms and so forth. Some simple and polyphenols found in honey, namely, caffeic acid (CA), caffeic acid phenyl esters (CAPE), chrysin (CR), galangin (GA), quercetin $(\mathrm{QU})$, kaempferol (KP), acacetin (AC), pinocembrin (PC), pinobanksin $(\mathrm{PB})$, and apigenin (AP), have evolved as promising pharmacological agents in prevention and treatment of cancer [62]. The antioxidant activity of Trigona carbonaria honey from Australia is high at 233.96 50.95 microM Trolox equivalents [96]. The antioxidant activity of four honey samples from different floral sources showed high antioxidant properties tested by different essay methods [97]. Dark honey had higher phenolic compounds and antioxidant activity than clear honey [98]. The amino acid composition of honey is an indicator of the toxic radical scavenging capacity [99].

\section{Honey as Potential Use in "Cancer Therapy"}

Honey may provide the basis for the development of novel therapeutics for patients with cancer and cancerrelated tumors. Jungle honey fragments were shown to have chemotactic induction for neutrophils and reactive oxygen species (ROS), proving its antitumor activity [67]. Recent studies on human breast [100], cervical [100], oral [101], and 
osteosarcoma [101] cancer cell lines using Malaysian jungle honey showed significant anticancer activity. Honey has been shown to have antineoplastic activity in an experimental bladder model in vivo and in vitro [102].

Honey is rich in flavonoids $[62,103]$. Flavanoids have created a lot of interests among researchers because of its anticancer properties. The mechanisms suggested are rather diverse such as various signaling pathways [104], including stimulation of TNF-alpha (tumor necrosis factor-alpha) release [105], inhibition of cell proliferation, induction of apoptosis [106], and cell cycle arrest [107] as well as inhibition of lipoprotein oxidation [108]. Honey is thought to mediate these beneficial effects due to its major components such as chrysin [104] and other flavonoids [109]. These differences are explainable as honeys are of various floral sources, and each floral source may exhibit different active compounds. Though honey has other substances of which the most predominant are a mixture of sugars (fructose, glucose, maltose, and sucrose) [110] which itself is carcinogenic [111], it is understandable that its beneficial effect on cancer raises skeptics. The mechanism on how honey has anti-cancer effect is an area of great interest recently. The effects of honeys on hormone-dependent cancers such as breast, endometrial, and prostate cancer and tumors remain largely unknown. There is a lot we can learn from nature [112]. For example, phytochemicals, such as genistein, lycopene, curcumin, epigallocatechin-gallate, and resveratrol have been studied to be used for treatment of prostate cancer [113]. Phytoestrogens constitute a group of plant-derived isoflavones and flavonoids, and honey belongs to plant phytoestrogen $[112,114]$.

\section{Conclusion}

There is now a sizeable evidence that honey is a natural immune booster, natural anti-inflammatory agent, natural antimicrobial agent, natural cancer "vaccine," and natural promoter for healing chronic ulcers and wounds; some of the risk factors for cancer development. Bee farming is a lucrative business. Honey and cancer have sustainable inverse relationship in the setting of developing nations where resources for cancer prevention and treatment are limited.

\section{References}

[1] M. Garcia, A. Jemal, E. Ward et al., Global Cancer Facts \& Figures 2007, American Cancer Society, Atlanta, Ga, USA, 2007.

[2] P. Boyle and B. Levin, World Cancer Report, WHO-IARC, 2008.

[3] G. C. Lim, "Overview of cancer in Malaysia," Japanese Journal of Clinical Oncology, vol. 32, pp. S37-S42, 2002.

[4] B. B. Yeole, "Trends in cancer incidence in female breast, cervix uteri, corpus uteri, and ovary in India," Asian Pacific Journal of Cancer Prevention, vol. 9, no. 1, pp. 119-122, 2008.

[5] C. Lepage, L. Remontet, G. Launoy et al., "Trends in incidence of digestive cancers in France," European Journal of Cancer Prevention, vol. 17, no. 1, pp. 13-17, 2008.

[6] S. Westlake and N. Cooper, "Cancer incidence and mortality: trends in the United Kingdom and constituent countries,
1993 to 2004," Health Statistics Quarterly, no. 38, pp. 33-46, 2008.

[7] C. Bouchardy, G. Fioretta, E. Rapiti et al., "Recent trends in prostate cancer mortality show a continuous decrease in several countries," International Journal of Cancer, vol. 123, no. 2, pp. 421-429, 2008.

[8] Z. Kabir and L. Clancy, "Lifestyle-related cancer death rates in Ireland: decreasing or increasing?" Irish Medical Journal, vol. 99, no. 2, pp. 40-42, 2006.

[9] D. M. Parkin, F. I. Bray, and S. S. Devesa, "Cancer burden in the year 2000. The global picture," European Journal of Cancer, vol. 37, supplement 8, pp. S4-S66, 2001.

[10] D. Belpomme, P. Irigaray, A. J. Sasco et al., "The growing incidence of cancer: role of lifestyle and screening detection (Review)," International Journal of Oncology, vol. 30, no. 5, pp. 1037-1049, 2007.

[11] A. Seow, S. W. Duffy, M. A. McGee, J. Lee, and H. P. Lee, "Breast cancer in Singapore: trends in incidence 1968-1992," International Journal of Epidemiology, vol. 25, no. 1, pp. 4045, 1996.

[12] A. Bener, H. Ayub, R. Kakil, and W. Ibrahim, "Patterns of cancer incidence among the population of Qatar: a worldwide comparative study," Asian Pacific Journal of Cancer Prevention, vol. 9, no. 1, pp. 19-24, 2008.

[13] L. M. Crane, M. Schaapveld, O. Visser, M. W. Louwman, J. T. Plukker, and G. M. van Dam, "Oesophageal cancer in The Netherlands: increasing incidence and mortality but improving survival," European Journal of Cancer, vol. 43, no. 9, pp. 1445-1451, 2007.

[14] D. M. Parkin, M. Almonte, L. Bruni, G. Clifford, M. P. Curado, and M. Piñeros, "Burden and trends of type-specific human papillomavirus infections and related diseases in the Latin America and Caribbean Region," Vaccine, vol. 26, supplement 11, pp. L1-L15, 2008.

[15] M. F. Yuen, J. L. Hou, and A. Chutaputti, "Hepatocellular carcinoma in the Asia Pacific region," Journal of Gastroenterology and Hepatology, vol. 24, no. 3, pp. 346-353, 2009.

[16] J. Chou, Y. C. Lin, J. Kim et al., "Nasopharyngeal carcinoma-review of the molecular mechanisms of tumorigenesis," Head and Neck, vol. 30, no. 7, pp. 946-963, 2008.

[17] H. Kuniyasu, Y. Kitadai, H. Mieno, and W. Yasui, "Helicobactor pylori infection is closely associated with telomere reduction in gastric mucosa," Oncology, vol. 65, no. 3, pp. 275-282, 2003.

[18] DCP2, "Controlling Cancer in Developing Countries; prevention and treatment strategies merit further study," 2007, http://www.dcp2.org/.

[19] C. K. Toh, "The changing epidemiology of lung cancer," Methods in Molecular Biology, vol. 472, pp. 397-411, 2009.

[20] H. A. Lando, B. Borrelli, L. C. Klein et al., "The landscape in global tobacco control research: a guide to gaining a foothold," American Journal of Public Health, vol. 95, no. 6, pp. 939-945, 2005.

[21] C. W. Warren, N. R. Jones, A. Peruga et al., "Global youth tobacco surveillance, 2000-2007," MMWR Surveillance Summaries, vol. 57, no. 1, pp. 1-28, 2008.

[22] R. Huxley, "The role of lifestyle risk factors on mortality from colorectal cancer in populations of the Asia-Pacific region," Asian Pacific Journal of Cancer Prevention, vol. 8, no. 2, pp. 191-198, 2007.

[23] L. Le Marchand, J. H. Hankin, L. R. Wilkens et al., "Combined effects of well-done red meat, smoking, and rapid Nacetyltransferase 2 and CYP1A2 phenotypes in increasing 
colorectal cancer risk," Cancer Epidemiology Biomarkers and Prevention, vol. 10, no. 12, pp. 1259-1266, 2001.

[24] T. Pischon, U. Nothlings, and H. Boeing, "Obesity and cancer," Proceedings of the Nutrition Society, vol. 67, no. 2, pp. 128-145, 2008.

[25] K. Rapp, J. Klenk, H. Ulmer et al., "Weight change and cancer risk in a cohort of more than 65,000 adults in Austria," Annals of Oncology, vol. 19, no. 4, pp. 641-648, 2008.

[26] G. K. Reeves, K. Pirie, V. Beral, J. Green, E. Spencer, and D. Bull, "Cancer incidence and mortality in relation to body mass index in the Million Women Study: cohort study," British Medical Journal, vol. 335, no. 7630, p. 1134, 2007.

[27] T. Bjorge, A. Engeland, S. Tretli, and E. Weiderpass, "Body size in relation to cancer of the uterine corpus in 1 million Norwegian women," International Journal of Cancer, vol. 120, no. 2, pp. 378-383, 2007.

[28] C. K. McCourt, D. G. Mutch, R. K. Gibb et al., "Body mass index: relationship to clinical, pathologic and features of microsatellite instability in endometrial cancer," Gynecologic Oncology, vol. 104, no. 3, pp. 535-539, 2007.

[29] S. Dogan, X. Hu, Y. Zhang, N. J. Maihle, J. P. Grande, and M. P. Cleary, "Effects of high-fat diet and/or body weight on mammary tumor leptin and apoptosis signaling pathways in MMTV-TGF-alpha mice," Breast Cancer Research, vol. 9, no. 6, p. R91, 2007.

[30] J. Ahn, A. Schatzkin, J. V. Lacey Jr. et al., "Adiposity, adult weight change, and postmenopausal breast cancer risk," Archives of Internal Medicine, vol. 167, no. 19, pp. 2091-2102, 2007.

[31] A. A. Moghaddam, M. Woodward, and R. Huxley, "Obesity and risk of colorectal cancer: a meta-analysis of 31 studies with 70,000 events," Cancer Epidemiology Biomarkers and Prevention, vol. 16, no. 12, pp. 2533-2547, 2007.

[32] S. Amemori, A. Ootani, S. Aoki et al., "Adipocytes and preadipocytes promote the proliferation of colon cancer cells in vitro," American Journal of Physiology, vol. 292, no. 3, pp. G923-G929, 2007.

[33] S. Low, M. C. Chin, and M. Deurenberg-Yap, "Review on epidemic of obesity," Annals of the Academy of Medicine, Singapore, vol. 38, no. 1, pp. 57-65, 2009.

[34] S. M. Nazri, M. K. Imran, I. M. Ismail, and A. A. Faris, "Prevalence of overweight and self-reported chronic diseases among residents in Pulau Kundur, Kelantan, Malaysia," Southeast Asian Journal of Tropical Medicine and Public Health, vol. 39, no. 1, pp. 162-167, 2008.

[35] A. Jackson, C. Cole, J. Esquiro, and M. Edwards, "Obesity in primary care patients in Kelantan, Malaysia: prevalence, and patients' knowledge and attitudes," Southeast Asian Journal of Tropical Medicine and Public Health, vol. 27, no. 4, pp. 776779, 1996.

[36] N. H. Othman, Z. M. Nor, and B. M. Biswal, "Is Kelantan joining the global cancer epidemic?-Experience from hospital Universiti Sains Malaysia; 1987-2007," Asian Pacific Journal of Cancer Prevention, vol. 9, no. 3, pp. 473-478, 2008.

[37] R. T. Jung, "Obesity as a disease," British Medical Bulletin, vol. 53, no. 2, pp. 307-321, 1997.

[38] A. Grandone, A. Amato, C. Luongo, N. Santoro, L. Perrone, and E. M. del Giudice, "High-normal fasting glucose levels are associated with increased prevalence of impaired glucose tolerance in obese children," Journal of Endocrinological Investigation, vol. 31, no. 12, pp. 1098-1102, 2008.

[39] M. Mafauzy, N. Mokhtar, W. B. Wan Mohamad, and M. Musalmah, "Diabetes mellitus and associated cardiovascular risk factors in North-East Malaysia," Asia-Pacific Journal of Public Health, vol. 11, no. 1, pp. 16-19, 1999.

[40] A. Zaini, "Where is Malaysia in the midst of the Asian epidemic of diabetes mellitus?" Diabetes Research and Clinical Practice, vol. 50, supplement 2, pp. S23-S28, 2000.

[41] M. Mafauzy, "Diabetes mellitus in Malaysia," Medical Journal of Malaysia, vol. 61, no. 4, pp. 397-398, 2006.

[42] N. H. Othman and A. A. Zin, "Association of colorectal carcinoma with metabolic diseases; experience with 138 cases from Kelantan, Malaysia," Asian Pacific Journal of Cancer Prevention, vol. 9, no. 4, pp. 747-751, 2008.

[43] A. Seow, J. M. Yuan, W. P. Koh, H. P. Lee, and M. C. $\mathrm{Yu}$, "Diabetes mellitus and risk of colorectal cancer in the Singapore Chinese Health Study," Journal of the National Cancer Institute, vol. 98, no. 2, pp. 135-138, 2006.

[44] Y. X. Yang, S. Hennessy, and J. D. Lewis, "Type 2 diabetes mellitus and the risk of colorectal cancer," Clinical Gastroenterology and Hepatology, vol. 3, no. 6, pp. 587-594, 2005.

[45] R. L. Ahmed, K. H. Schmitz, K. E. Anderson, W. D. Rosamond, and A. R. Folsom, "The metabolic syndrome and risk of incident colorectal cancer," Cancer, vol. 107, no. 1, pp. 28-36, 2006.

[46] C. Carrillo-Infante, G. Abbadessa, L. Bagella, and A. Giordano, "Viral infections as a cause of cancer (Review)," International Journal of Oncology, vol. 30, no. 6, pp. 15211528, 2007.

[47] K. Siddique, S. Bhandari, and G. Harinath, "Epsteln-Barr virus (EBV) posittie anal B cell lymphoma: a case report and review of literature," Annals of the Royal College of Surgeons of England, vol. 92, no. 3, pp. W7-W9, 2010.

[48] M. E. McLaughlin-Drubin and K. Munger, "Viruses associated with human cancer," Biochimica et Biophysica Acta, vol. 1782, no. 3, pp. 127-150, 2008.

[49] J. Hrbacek, M. Urban, E. Hamsikova et al., "Serum antibodies against genitourinary infectious agents in prostate cancer and benign prostate hyperplasia patients: a case-control study," BMC Cancer, vol. 11, article 53, 2011.

[50] V. Sharma, V. S. Chauhan, G. Nath, A. Kumar, and V. K. Shukla, "Role of bile bacteria in gallbladder carcinoma," Hepato-Gastroenterology, vol. 54, no. 78, pp. 1622-1625, 2007.

[51] S. J. Hooper, M. J. Wilson, and S. J. Crean, "Exploring the link between microorganisms and oral cancer: a systematic review of the literature," Head and Neck, vol. 31, no. 9, pp. 1228-1239, 2009.

[52] H. Kuper, H. O. Adami, and D. Trichopoulos, "Infections as a major preventable cause of human cancer," Journal of Internal Medicine, vol. 249, no. 741, pp. 61-74, 2001.

[53] S. M. Cohen, D. T. Purtilo, and L. B. Ellwein, "Ideas in pathology. Pivotal role of increased cell proliferation in human carcinogenesis," Modern Pathology, vol. 4, no. 3, pp. 371-382, 1991 .

[54] F. Bray and B. Moller, "Predicting the future burden of cancer," Nature Reviews Cancer, vol. 6, no. 1, pp. 63-74, 2006.

[55] S. Franceschi and C. La Vecchia, "Cancer epidemiology in the elderly," Critical Reviews in Oncology/Hematology, vol. 39, no. 3, pp. 219-226, 2001.

[56] M. E. Asuquo, A. M. Udosen, I. A. Ikpeme et al., "Cutaneous squamous cell carcinoma in Calabar, Southern Nigeria," Clinical and Experimental Dermatology, vol. 34, no. 8, pp. 870-873, 2009.

[57] M. Asuquo, G. Ugare, G. Ebughe, and P. Jibril, "Marjolin's ulcer: the importance of surgical management of chronic 
cutaneous ulcers," International Journal of Dermatology, vol. 46, supplement 2, pp. 29-32, 2007.

[58] L. Yao, N. Datta, F. A. Tomás-Barberán, F. Ferreres, I. Martos, and R. Singanusong, "Flavonoids, phenolic acids and abscisic acid in Australian and New Zealand Leptospermum honeys," Food Chemistry, vol. 81, no. 2, pp. 159-168, 2003.

[59] K. Pyrzynska and M. Biesaga, "Analysis of phenolic acids and flavonoids in honey," TrAC Trends in Analytical Chemistry, vol. 28, no. 7, pp. 893-902, 2009.

[60] M. O. Iurlina, A. I. Saiz, R. Fritz, and G. D. Manrique, "Major flavonoids of Argentinean honeys. Optimisation of the extraction method and analysis of their content in relationship to the geographical source of honeys," Food Chemistry, vol. 115, no. 3, pp. 1141-1149, 2009.

[61] M. Valko, D. Leibfritz, J. Moncol, M. T. D. Cronin, M. Mazur, and J. Telser, "Free radicals and antioxidants in normal physiological functions and human disease," The International Journal of Biochemistry \& Cell Biology, vol. 39, no. 1, pp. 44-84, 2007.

[62] S. K. Jaganathan and M. Mandal, "Antiproliferative effects of honey and of its polyphenols: a review," Journal of Biomedicine and Biotechnology, vol. 2009, Article ID 830616, 13 pages, 2009.

[63] A. J. Tonks, R. A. Cooper, K. P. Jones, S. Blair, J. Parton, and A. Tonks, "Honey stimulates inflammatory cytokine production from monocytes," Cytokine, vol. 21, no. 5, pp. 242-247, 2003.

[64] A. J. Tonks, E. Dudley, N. G. Porter et al., "A 5.8-kDa component of manuka honey stimulates immune cells via TLR4," Journal of Leukocyte Biology, vol. 82, no. 5, pp. 11471155, 2007.

[65] N. S. Al-Waili and A. Haq, "Effect of honey on antibody production against thymus-dependent and thymus-independent antigens in primary and secondary immune responses," Journal of Medicinal Food, vol. 7, no. 4, pp. 491-494, 2004.

[66] N. S. Al-Waili, T. N. Al-Waili, A. N. Al-Waili, and K. S. Saloom, "Influence of natural honey on biochemical and hematological variables in AIDS: a case study," The Scientific World Journal, vol. 6, pp. 1985-1989, 2006.

[67] M. Fukuda, K. Kobayashi, Y. Hirono et al., "Jungle honey enhances immune function and antitumor activity," Evidence-Based Complementary and Alternative Medicine, vol. 2011, Article ID 908743, 2011.

[68] N. S. Al-Waili, "Clinical and mycological benefits of topical application of honey, olive oil and beeswax in diaper dermatitis," Clinical Microbiology and Infection, vol. 11, no. 2, pp. 160-163, 2005.

[69] B. Heppermann, "Towards evidence based emergency medicine: Best BETs from the Manchester Royal Infirmary. Bet 3. Honey for the symptomatic relief of cough in children with upper respiratory tract infections," Emergency Medicine Journal, vol. 26, no. 7, pp. 522-523, 2009.

[70] N. S. Al-Waili, “Topical application of natural honey, beeswax and olive oil mixture for atopic dermatitis or psoriasis: partially controlled, single-blinded study," Complementary Therapies in Medicine, vol. 11, no. 4, pp. 226-234, 2003.

[71] A. Alnaqdy, A. Al-Jabri, Z. Al Mahrooqi, B. Nzeako, and H. Nsanze, "Inhibition effect of honey on the adherence of Salmonella to intestinal epithelial cells in vitro," International Journal of Food Microbiology, vol. 103, no. 3, pp. 347-351, 2005.

[72] H. K. English, A. R. Pack, and P. C. Molan, "The effects of manuka honey on plaque and gingivitis: a pilot study,"
Journal of the International Academy of Periodontology, vol. 6, no. 2, pp. 63-67, 2004.

[73] P. C. Molan, "The potential of honey to promote oral wellness," General dentistry, vol. 49, no. 6, pp. 584-589, 2001.

[74] J. Hon, "Using honey to heal a chronic wound in a patient with epidermolysis bullosa," British Journal of Nursing, vol. 14, no. 19, pp. S4-S12, 2005.

[75] A. F. Henriques, R. E. Jenkins, N. F. Burton, and R. A. Cooper, "The intracellular effects of manuka honey on Staphylococcus aureus," European Journal of Clinical Microbiology and Infectious Diseases, vol. 29, no. 1, pp. 45-50, 2010.

[76] P. L. Miorin, N. C. Levy Jr., A. R. Custodio, W. A. Bretz, and M. C. Marcucci, "Antibacterial activity of honey and propolis from Apis mellifera and Tetragonisca angustula against Staphylococcus aureus," Journal of Applied Microbiology, vol. 95, no. 5, pp. 913-920, 2003.

[77] V. M. French, R. A. Cooper, and P. C. Molan, "The antibacterial activity of honey against coagulase-negative staphylococci," Journal of Antimicrobial Chemotherapy, vol. 56, no. 1, pp. 228-231, 2005.

[78] N. S. Al-Waili, "Investigating the antimicrobial activity of natural honey and its effects on the pathogenic bacterial infections of surgical wounds and conjunctiva," Journal of Medicinal Food, vol. 7, no. 2, pp. 210-222, 2004.

[79] A. A. Al-Jabri, S. A. Al-Hosni, B. C. Nzeako, Z. H. AlMahrooqi, and H. Nsanze, "Antibacterial activity of Omani honey alone and in combination with gentamicin," Saudi Medical Journal, vol. 26, no. 5, pp. 767-771, 2005.

[80] N. S. Al-Waili, M. Akmal, F. S. Al-Waili, K. Y. Saloom, and A. Ali, "The antimicrobial potential of honey from United Arab Emirates on some microbial isolates," Medical Science Monitor, vol. 11, no. 12, pp. BR433-BR438, 2005.

[81] A. A. Asadi-Pooya, M. R. Pnjehshahin, and S. Beheshti, "The antimycobacterial effect of honey: an in vitro Study," Rivista di Biologia, vol. 96, no. 3, pp. 491-495, 2003.

[82] T. Alandejani, J. Marsan, W. Ferris, R. Slinger, and F. Chan, "Effectiveness of honey on Staphylococcus aureus and Pseudomonas aeruginosa biofilms," Otolaryngology-Head and Neck Surgery, vol. 141, no. 1, pp. 114-118, 2009.

[83] N. S. Al-Waili, "Topical honey application versus acyclovir for the treatment of recurrent herpes simplex lesions," Medical Science Monitor, vol. 10, no. 8, pp. MT94-MT98, 2004.

[84] P. Codoner-Franch, V. Valls-Belles, A. Arilla-Codoner, and E. Alonso-Iglesias, "Oxidant mechanisms in childhood obesity: the link between inflammation and oxidative stress," Translational Research, vol. 158, no. 6, pp. 369-384, 2011.

[85] N. Yaghoobi, N. Al-Waili, M. Ghayour-Mobarhan et al., "Natural honey and cardiovascular risk factors; effects on blood glucose, cholesterol, triacylglycerole, CRP, and body weight compared with sucrose," The Scientific World Journal, vol. 8, pp. 463-469, 2008.

[86] A. Sharp, "Beneficial effects of honey dressings in wound management," Nursing Standard, vol. 24, no. 7, pp. 66-72, 2009.

[87] K. F. Cutting, "Honey and contemporary wound care: an overview," Ostomy Wound Management, vol. 53, no. 11, pp. 49-54, 2007.

[88] R. A. Cooper, P. C. Molan, L. Krishnamoorthy, and K. G. Harding, "Manuka honey used to heal a recalcitrant surgical wound," European Journal of Clinical Microbiology and Infectious Diseases, vol. 20, no. 10, pp. 758-759, 2001. 
[89] P. C. Molan, "Potential of honey in the treatment of wounds and burns," American Journal of Clinical Dermatology, vol. 2, no. 1, pp. 13-19, 2001.

[90] D. G. Armstrong, "Manuka honey improved wound healing in patients with sloughy venous leg ulcers," Evidence-Based Medicine, vol. 14, no. 5, p. 148, 2009.

[91] G. Gethin and S. Cowman, "Bacteriological changes in sloughy venous leg ulcers treated with manuka honey or hydrogel: an RCT," Journal of Wound Care, vol. 17, no. 6, pp. 241-247, 2008.

[92] G. T. Gethin, S. Cowman, and R. M. Conroy, "The impact of manuka honey dressings on the surface $\mathrm{pH}$ of chronic wounds," International Wound Journal, vol. 5, no. 2, pp. 185194, 2008.

[93] M. Wijesinghe, M. Weatherall, K. Perrin, and R. Beasley, "Honey in the treatment of burns: a systematic review and meta-analysis of its efficacy," New Zealand Medical Journal, vol. 122, no. 1295, pp. 47-60, 2009.

[94] J. J. Eddy, M. D. Gideonsen, and G. P. Mack, "Practical considerations of using topical honey for neuropathic diabetic foot ulcers: a review," Wisconsin Medical Journal, vol. 107, no. 4, pp. 187-190, 2008.

[95] R. Ingle, J. Levin, and K. Polinder, "Wound healing with honey-a randomised controlled trial," South African Medical Journal, vol. 96, no. 9, pp. 831-835, 2006.

[96] L. P. Oddo, T. A. Heard, A. Rodriguez-Malaver et al., "Composition and antioxidant activity of Trigona carbonaria honey from Australia," Journal of Medicinal Food, vol. 11, no. 4, pp. 789-794, 2008.

[97] A. G. Hegazi and F. K. Abd El-Hady, "Influence of honey on the suppression of human low density lipoprotein (LDL) peroxidation (In vitro)," Evidence-Based Complementary and Alternative Medicine, vol. 6, no. 1, pp. 113-121, 2009.

[98] L. Estevinho, A. P. Pereira, L. Moreira, L. G. Dias, and E. Pereira, "Antioxidant and antimicrobial effects of phenolic compounds extracts of Northeast Portugal honey," Food and Chemical Toxicology, vol. 46, no. 12, pp. 3774-3779, 2008.

[99] A. R. Perez, M. T. Iglesias, E. Pueyo, M. Gonzalez, and C. de Lorenzo, "Amino acid composition and antioxidant capacity of Spanish honeys," Journal of Agricultural and Food Chemistry, vol. 55, no. 2, pp. 360-365, 2007.

[100] A. N. Fauzi, M. N. Norazmi, and N. S. Yaacob, "Tualang honey induces apoptosis and disrupts the mitochondrial membrane potential of human breast and cervical cancer cell lines," Food and Chemical Toxicology, vol. 49, no. 4, pp. 871878, 2011.

[101] A. A. Ghashm, N. H. Othman, M. N. Khattak, N. M. Ismail, and R. Saini, "Antiproliferative effect of Tualang honey on oral squamous cell carcinoma and osteosarcoma cell lines," BMC Complementary and Alternative Medicine, vol. 10, article 49, 2010.

[102] T. Swellam, N. Miyanaga, M. Onozawa et al., "Antineoplastic activity of honey in an experimental bladder cancer implantation model: in vivo and in vitro studies," International Journal of Urology, vol. 10, no. 4, pp. 213-219, 2003.

[103] A. M. Gomez-Caravaca, M. Gomez-Romero, D. ArraezRoman, A. Segura-Carretero, and A. Fernandez-Gutierrez, "Advances in the analysis of phenolic compounds in products derived from bees," Journal of Pharmaceutical and Biomedical Analysis, vol. 41, no. 4, pp. 1220-1234, 2006.

[104] K. J. Woo, Y. J. Jeong, J. W. Park, and T. K. Kwon, “Chrysininduced apoptosis is mediated through caspase activation and Akt inactivation in U937 leukemia cells," Biochemical and Biophysical Research Communications, vol. 325, no. 4, pp. 1215-1222, 2004.

[105] A. Tonks, R. A. Cooper, A. J. Price, P. C. Molan, and K. P. Jones, "Stimulation of TNF- $\alpha$ release in monocytes by honey," Cytokine, vol. 14, no. 4, pp. 240-242, 2001.

[106] S. K. Jaganathan and M. Mandal, "Involvement of nonprotein thiols, mitochondrial dysfunction, reactive oxygen species and p53 in honey-induced apoptosis," Investigational New Drugs, vol. 28, no. 5, pp. 624-633, 2010.

[107] E. Pichichero, R. Cicconi, M. Mattei, M. G. Muzi, and A. Canini, "Acacia honey and chrysin reduce proliferation of melanoma cells through alterations in cell cycle progression," International Journal of Oncology, vol. 37, no. 4, pp. 973-981, 2010.

[108] N. Gheldof and N. J. Engeseth, "Antioxidant capacity of honeys from various floral sources based on the determination of oxygen radical absorbance capacity and inhibition of in vitro lipoprotein oxidation in human serum samples," Journal of Agricultural and Food Chemistry, vol. 50, no. 10, pp. 30503055, 2002.

[109] S. K. Jaganathan, S. M. Mandal, S. K. Jana, S. Das, and M. Mandal, "Studies on the phenolic profiling, anti-oxidant and cytotoxic activity of Indian honey: in vitro evaluation," Natural Product Research, vol. 24, no. 14, pp. 1295-1306, 2010.

[110] A. M. Aljadi and M. Y. Kamaruddin, "Evaluation of the phenolic contents and antioxidant capacities of two Malaysian floral honeys," Food Chemistry, vol. 85, no. 4, pp. 513-518, 2004.

[111] J. C. Heuson, N. Legros, and R. Heimann, "Influence of insulin administration on growth of the 7,12dimethylbenz(a)anthracene-induced mammary carcinoma in intact, oophorectomized, and hypophysectomized rats," Cancer Research, vol. 32, no. 2, pp. 233-238, 1972.

[112] P. Moutsatsou, "The spectrum of phytoestrogens in nature: our knowledge is expanding," Hormones, vol. 6, no. 3, pp. 173-193, 2007.

[113] E. C. Von Low, F. G. Perabo, R. Siener, and S. C. Muller, "Facts and fiction of phytotherapy for prostate cancer: a critical assessment of preclinical and clinical data," In Vivo, vol. 21, no. 2, pp. 189-204, 2007.

[114] S. S. Zaid, S. A. Sulaiman, K. N. Sirajudeen, and N. H. Othman, "The effects of tualang honey on female reproductive organs, tibia bone and hormonal profile in ovariectomised rats-animal model for menopause," BMC Complementary and Alternative Medicine, vol. 10, article 82, 2010. 


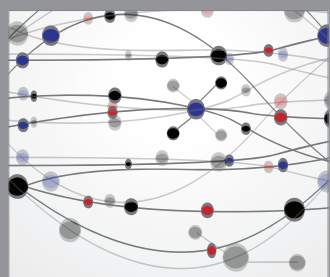

The Scientific World Journal
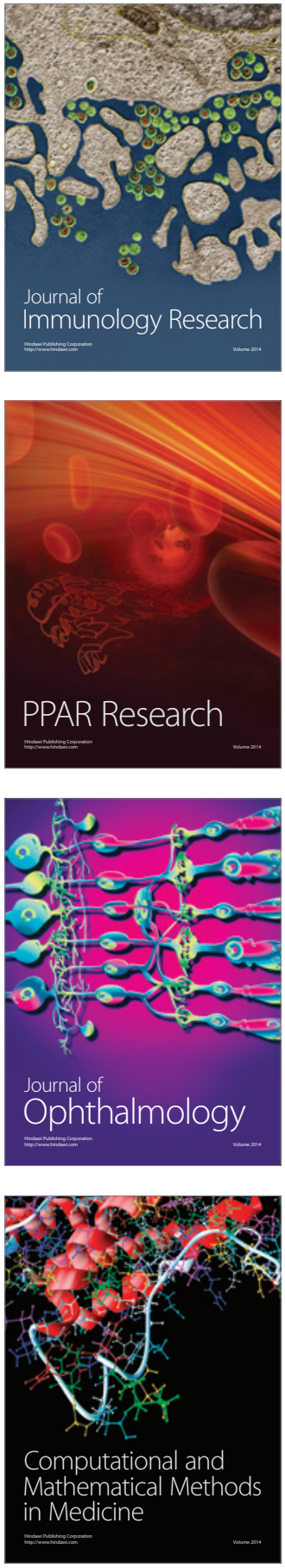

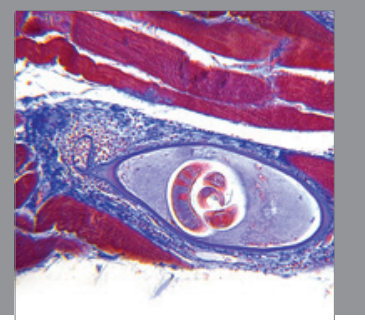

Gastroenterology

Research and Practice
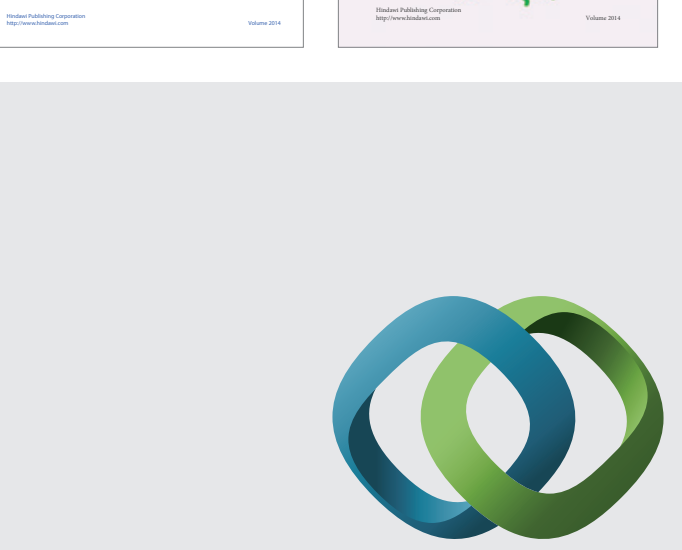

\section{Hindawi}

Submit your manuscripts at

http://www.hindawi.com
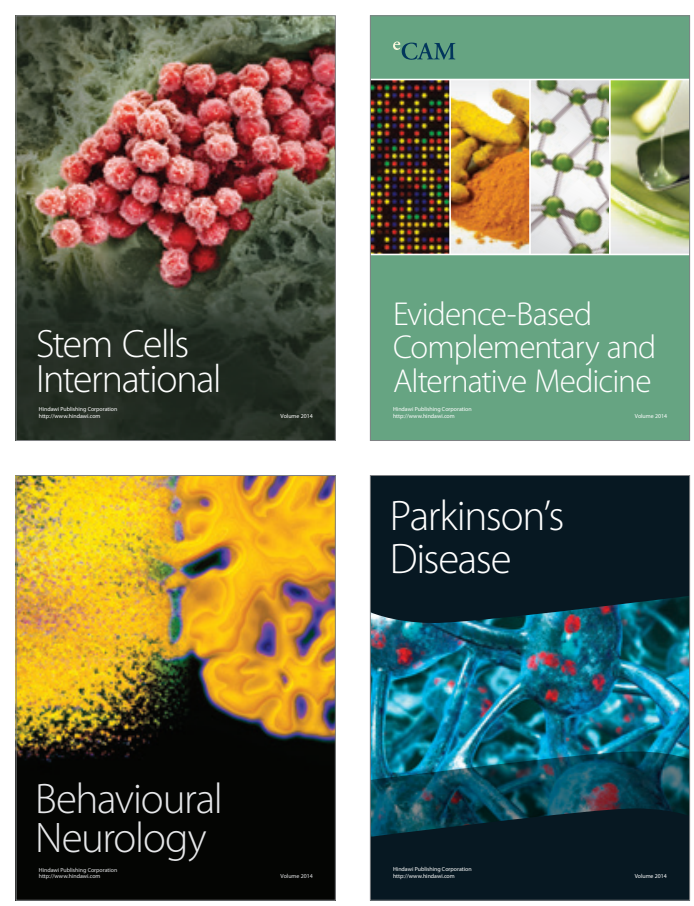

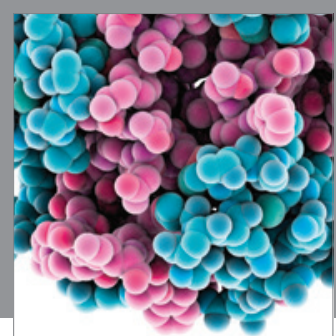

Journal of
Diabetes Research

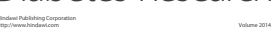

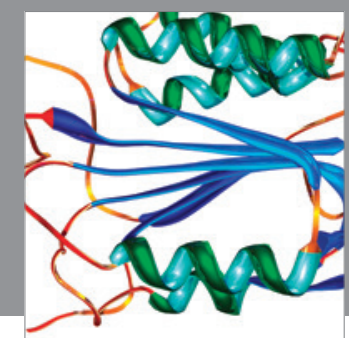

Disease Markers
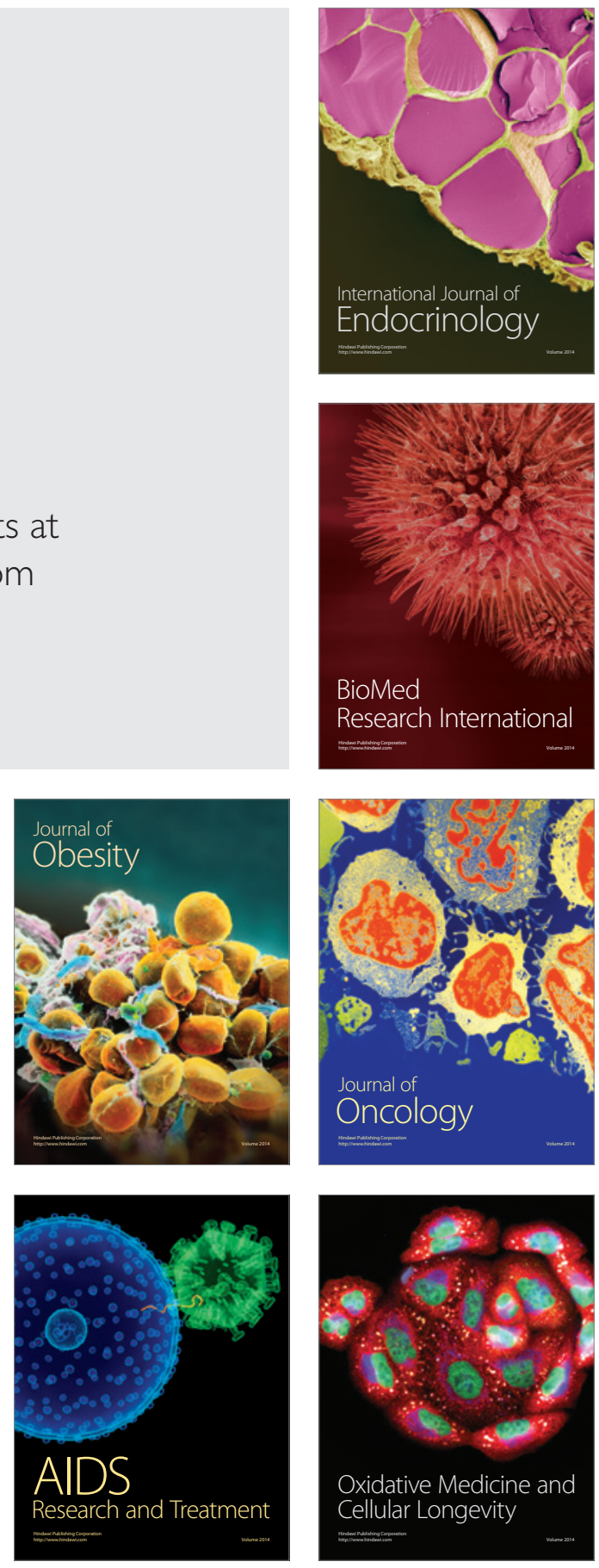